\title{
Determination of Static Fracture Toughness of Nettle Fibre (Urtica Dioica) / Polymethylmethacrylate Composites Using Different Fracture Methods
}

\author{
Kenan BÜYÜKKAYA*, Faruk GÜNER** \\ *Giresun University, Technical Sciences Vocational High School, Gazipaşa Yerleşkesi,28100 Giresun, Turkey, \\ E-mail: kenan.buyukkaya@giresun.edu.tr \\ **Giresun University, Department of Engineering, Güre, Giresun, E-mail: faruk.guner@giresun.edu.tr \\ cross $^{\text {ref }}$ http://dx.doi.org/10.5755/j01.mech.26.2.23308
}

\section{Introduction}

The use of natural fibres is becoming increasingly more popular in composite materials manufacturing. These materials are widely used in industries such as construction, electronics, sports, and automotive [1]. Polymer composites reinforced with natural fibres are preferable for such purposes because of their positive features such as affordability, mechanical properties, chemical strength, light weight, biodegradability, and acoustic and thermal properties [1-2].

The other industrial alternative to natural fibres are synthetic fibres. If synthetic and natural fibres are compared, the latter can be seen to have many advantages such as lower density, lower cost, higher ease of processing, higher renewability, lower $\mathrm{CO} 2$ emissions, higher weight strength, higher specific modules and ease of recycling [3]. Because of these advantages, the demand for natural fibres has gradually increased in recent years; indeed, it is estimated that the use of these fibres will increase six-fold in Europe till 2024 [4].

Many researchers have investigated the use of natural fibres (e.g., cellulose, jute, sisal, husk, and coconut) in preference to polymeric composites, and made positive comments about their structure-feature relationships [5-9]. Thermoset matrices such as polyester, acrylic and epoxy have been used to evaluate the linear elastic fracture toughness of composites [10-14]. The general characteristics of these matrices are that they exhibit brittle fracture behaviour and that the deformation zone at the crack mouth is minimized at breakage. Thus, linear elastic fracture toughness conditions are realized using these kinds of matrices. Polymethyl-methacrylate (PMMA) is preferred for ease of application and its low cost.

Different sampling and loading methods are available to determine fracture toughness. Fracture toughness can be determined by Compliance and Initial Notch methods, using different a/w ratios (ratio of notch depth to width of sample) in bending tests $[15,16]$. In the tensile test, compact test samples, single edge notched samples, etc., methods can be used.

In the present study, we will attempt to determine the breaking behaviour of nettle fibre-reinforced composites using various methods. To this end, the bending tests and compact tensile tests of notched stick samples were carried out in accordance with ASTM E-399 standards. The composites were examined in terms of reinforcement mechanisms, elasticity module, flexural stress, and fracture toughness. The fracture toughness tests were performed using the bending test by standard sample and Compliance test sample. Initial notch was used in the compact tensile test. The microstructures related to the reinforcement and fracture damage processes were revealed. The fibre added to the polymethyl-methacrylate matrix increased the fracture strength of composite four-fold.

\section{Experimental details}

\subsection{Preparation of samples}

The fibres were obtained from the nettle (Urtica dioica) which is a perennial plant naturally growing in the Eastern Black Sea region. No chemical procedure was employed either in obtaining or in the following phases of the fibre extraction process. The traditional method was used to obtain the fibres from the nettle, and a manual peeling method was utilized while fibres were being separated from the woody structure. As stated in the literature, the partially manual peeling method is intended to prevent possible mechanical damage to the fibre [19]. For the traditional method, harvesting, drying, composting, manual peeling, and hackling were performed, respectively [20, 21]. Some of the physical and mechanical properties of nettle fibres, as taken from the literature, are listed in Table 1 [22].

Table 1

Properties of the nettle fibres

\begin{tabular}{|c|c|}
\hline Property & Value \\
\hline Length, $\mathrm{mm}$ & $42-54$ \\
\hline Thickness, $\mu \mathrm{m}$ & $16-43$ \\
\hline Strength, $\mathrm{MPa}$ & $954-2234$ \\
\hline Young Mod., GPa & $59-119$ \\
\hline Elong.at Br., $\%$ & $1.5-6$ \\
\hline Density, gr/cm & 1.5 \\
\hline
\end{tabular}

Polymethyl-methacrylate (PMMA) was chosen as the matrix material for the composite samples. PMMA and its hardening materials were supplied from Otto Bock's distributor in Turkey (Otto Bock Medikal Hizmetler Mecidiyeköy Mah. Lati Lokum sok. Meriç Sitesi B Blok 30/B Şişli - İstanbul/TURKEY). The mechanical properties of standard PMMA are presented in Table 2 [23-24].

In order to prepare the experimental samples of nettle fibre/PMMA composites, the casting moulds were made of polytetrafluoroethylene (PTFE) material. The nettle fibres were cut into $5 \mathrm{~mm}$ lengths and mixed into the PMMA matrix material, which was prepared by adding $2 \%$ peroxide hardener material. The samples tested via the TPB 
test/Charphy method were poured into moulds according to ASTM E399 standards. Following the casting procedure, the moulds were closed and pressurized to $6.25 \mathrm{MPa}$. After the reaction had completed, the samples were removed from the mould and placed in an oven for 24 hours at $80^{\circ} \mathrm{C}$ to effect the final cure.

Table 2

Mechanical properties of standard PMMA

\begin{tabular}{|l|l|}
\hline Mechanical Property & Value \\
\hline Elongation at Break, \% & $0.5-5$ \\
\hline Hardness - Rockwell, M & 93 \\
\hline Impact strength, $\mathrm{kJ} / \mathrm{m}^{2}$ & 11 \\
\hline Poisson ratio & $0.35-0.40$ \\
\hline Elasticity module, $\mathrm{MPa}$ & 3300 \\
\hline Tensile strength, $\mathrm{MPa}$ & $60-70$ \\
\hline Fracture toughness, $\mathrm{MN} / \mathrm{m}^{3 / 2}$ & $0.7-1.7$ \\
\hline
\end{tabular}

The samples were processed into standard sizes on the automatic benches, as can be seen in Fig. 1. Standard notches $(a / W=0.1,0.2,0.3$, and 0.4$)$ were created in the fracture toughness samples. The notches were prepared with a special razor blade constructed in the laboratory. The special razor blade tool was made from very fine sharpened saws.

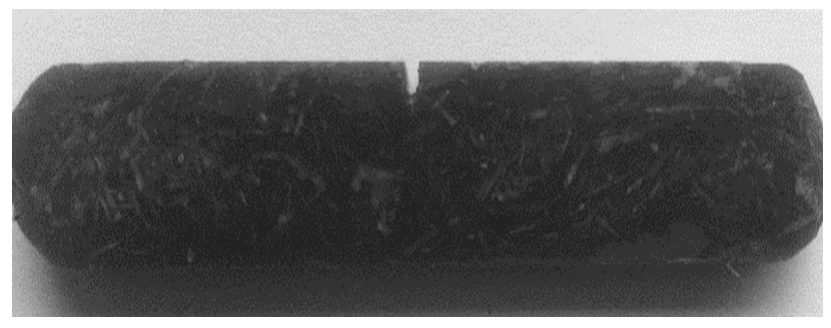

Fig. 1 Processed SENB Sample

\subsection{Characterization}

Fourier-Transform Infrared Spectroscopic (FTIR) analyses of the composites were performed using a Perkin Elmer Spectrum1400 spectrometer at a scanning range of 4000-650 cm-1 at room temperature. The test was performed at a $2 \mathrm{~cm}-1$ resolution with 10 scanning repeats.

$\mathrm{X}$-Ray diffraction was performed using a copperradiation advanced diffractometer (Europe $600 \mathrm{XRD}$ ). The device was run in CuKa mode, at $40 \mathrm{kV}$ and $30 \mathrm{~mA}$. The scanning range was $10-30^{\circ}$ with a $0.02^{\circ}$ interval, and scanning rate was set to 0.4 min-1.

The gold plating procedure was applied in order to obtain scanning electron microscopic images using JEOL Ltd.'s JSM-5910. SEM analysis was performed by examining the fractured surfaces of nettle fibre/PMMA composites in detail.

In order to determine the diameters of the fibres, an optical microscope (OLYMPUS BX 53) was utilized. The diameters of the fibres, as determined from 50 pieces of sample ranged from approximately $30-80 \mu \mathrm{m}$ in this study.

\subsection{Assessment of fibre volumetric fraction}

Volumetric fraction is the most important parameter when determining the mechanical properties of composites. Fibre volumetric fraction $V_{f}$ can be calculated using Eq. (1), if the fibre density is known exactly:

$$
V_{f}=M_{f} / V_{c} \cdot \rho_{f},
$$

where: $M_{f}$ is the fibre mass; $V_{c}$ is the composite volume; $\rho_{f}$ is the fibre density. On the other hand, the porosity of natural fibres and the spaces inside the composite have to be considered, therefore the statement in Eq. (2) was accepted as a better tool from measuring the volumetric fraction $V_{f}$ of composites reinforced with natural fibres $[25,26]$ :

$$
V_{f}=\left(V_{c}-\left(M_{c}-M_{f}\right) / \rho_{r}\right) / V_{c}
$$

where: $M_{c}$ is the mass of the composite and $\rho_{r}$ is the density of the cured polymer. Volume and weight ratios of the matrix and nettle fibre calculated via Eq. (2) are reported in Table 3.

Table 3

Volume and weight ratios of the matrix and nettle fibres

\begin{tabular}{|c|c|c|c|}
\hline Fibre $V_{f}, \%$ & Fibre $W_{f}, \%$ & Matrix $V_{m}$ & Matrix $W_{m}$ \\
\hline 2.5 & 2.70 & 97.5 & 97.30 \\
\hline 5 & 5.40 & 95 & 94.60 \\
\hline 7.5 & 8.12 & 92.5 & 91.88 \\
\hline 10 & 10.8 & 90 & 89.20 \\
\hline
\end{tabular}

The crystallinity index $\mathrm{CrI}$ of nettle fibre was determined using the Segal empirical method [27, 28]. This method enables the rapid and straightforward calculation of the crystallinity index via Eq. (3):

$$
C r I=\left(I_{002}-I_{a m}\right) x 100 / I_{002},
$$

where: $I_{002}$ is the maximum point of peak of Crystal 002, and $I_{a m}$ is the minimum point of the amorphous material between peaks 101 and 002 .

\subsection{Tension and TPB Tests}

The processed rectangular sticks with dimensions of $70 \times 6 \times 12 \mathrm{~mm}$ were subjected to bending resistance $\left(\sigma_{f}\right)$, bending module $\left(E_{f}\right)$, and fracture toughness $\left(K_{I C}\right)$ using the TPB test with a distance of $48 \mathrm{~mm}$ between the bearings. In order to measure the gap at the tip of the crack, a clip gauge (SHIMADZU P701805) with a gauge length of $3 \mathrm{~mm}$, movement distance of $5 \mathrm{~mm}(\max .10 \mathrm{~Hz})$ at a speed of $1.0 \mathrm{~mm} / \mathrm{min}$ was utilized. The samples with $0.1,0.2,0.3$, and $0.4 \mathrm{a} / \mathrm{W}$ ratios were used for $K_{I C}$ measurement, while sharp cutters were used to create the sharp tip of the crack. The bending test was performed using a universal testing device at a speed of $1.0 \mathrm{~mm} / \mathrm{min}$. The testing machine (Shimadzu ehf-lv020k2-0) is shown in Fig. 2. The tests for each composition were performed using a minimum of four samples. $\sigma_{f}, E_{f}$, and $K_{I C}$ were calculated in each instance using the equations below [29].

$$
\begin{gathered}
\sigma_{F}=\frac{3 P_{m} S}{2 W D^{2}}, \\
E_{F}=\frac{P_{m} S^{2}}{4 W D_{e}},
\end{gathered}
$$

where: $P_{m}$ is the load at the moment of breakage; $S$ is the distance between the bearings; $D$ is the sample thickness; $e$ is the deflection in the sample recorded by LVDT; $W$ is the sample width and $a$ is the crack length, in Eqs. (4-5). 


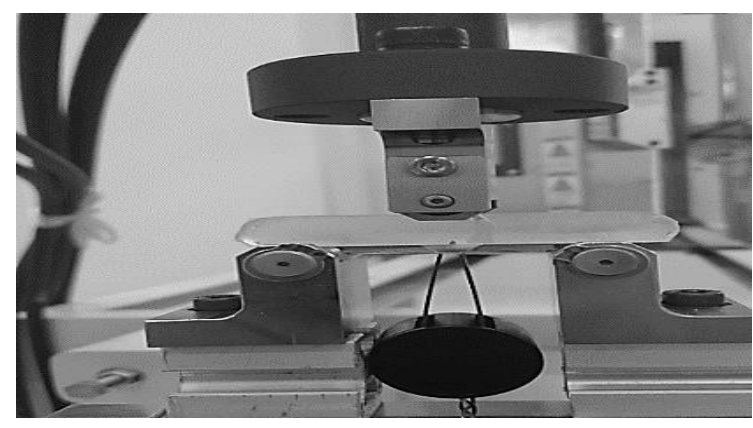

Fig. 2 Bending and fracture test setup (ESM1)

The fracture toughness tests were performed using the bending test with the standard sample and Compliance method sample. Eq. (6) was used to determine the fracture toughness via standard test samples [37]:

$$
K_{I C}=\frac{3 P S}{2 B W^{3 / 2}} f\left(\frac{a}{w}\right)
$$

where: $P_{m}$ is the load at fracture point, and $f(a / w)$ is the geometric correction factor given by Eq. (7).

The $C=f(a / w)$ function, which is a comparison of the compliance notch-to-depth ratio obtained from the curve in Fig. 11.

$$
f\left(\frac{a}{w}\right)=\frac{3(a / W)^{1 / 2}\left[1.99-(a / w)(1-(a / w)) x\left(2.15-3.93(a / w)+2.7(a / w)^{2}\right]\right.}{2(1+2 a / w)(1-a / w)^{3 / 2}} .
$$

While obtaining the results from the Compliance method, the load-displacement or load- Crack Mouth Opening Displacement $\left(C_{M O D}\right)$ graphs for samples with different notch depths were used. The compliance values $\left(C_{1}\right.$, $C_{2} \ldots C_{n}$ ) were calculated using Eq. (8). The load- $C_{M O D}$ curve is presented in Fig. 10.

$$
C=d C_{M O D} / d P
$$

The $C=f(a / w)$ function's derivative to $(a / w)$ was substituted into Eq. (9), and the sample $K_{I C}$ values were calculated:

$$
K_{I C}=\frac{E}{1-v^{2}} \frac{P}{2 b} \frac{d C}{d(a / w)},
$$

where: $E$ represents the sample modulus of elasticity; $P$ is the maximum load applied; $v$ is the Poisson ratio and $(d c /(d(a / w)))$ is the comparison gradient of the compliance notch-to-depth ratio.

The Compact Tension test $C_{T}$ was performed using $62.5 \times 50 \times 25 \mathrm{~mm}$ samples, which were processed to create the standards for the sharp notches. The Compact Tension tests were performed using a universal test device (SHIMADZU EHF-LV020K2-020) at a speed of $1.0 \mathrm{~mm} / \mathrm{min}$ and measuring the enlargement of the crack via clip-gauge. The fracture toughness was calculated using Eq. (10) $[10,11]$ :

$$
K_{I C}=\frac{P}{D \sqrt{w}} f\left(\frac{a}{w}\right)
$$

where: $w$ is the distance between the right edge and load line, and the geometrical correction factor $f$ can be expressed as:

$$
f(a / w)=\frac{(2+a / w)\left[0.866+4.64 a / w-13.32(a / w)^{2}+14.72(a / w)^{3}-5.6(a / w)^{4}\right]}{(1-a / w)^{3 / 2}}
$$

\section{Results and discussion}

\subsection{FTIR Analysis of Nettle Fibre}

The results of FTIR analysis of experimental samples are shown in Fig. 3. The spectra can be described as follows. The $750 \mathrm{~cm}^{-1}$ peak is thought to originate from the vibration of a $\mathrm{C}-\mathrm{C}$ bond. $\mathrm{C}-\mathrm{H}$ vibrations in aromatic rings and the $\mathrm{C}-\mathrm{O}$ vibration in primary alcohols can observed at around $1057 \mathrm{~cm}^{-1}$. The peak at $1420 \mathrm{~cm}^{-1}$ originates from the symmetrical bending of $\mathrm{CH} 2$. The absorption band at 1650 $1630 \mathrm{~cm}^{-1}$ occurs as a result of the vibration of water molecules in non-crystal regions of cellulose. The $2928 \mathrm{~cm}^{-1}$ peak might be correlated with the stretch vibration of methyl and methylene groups. The presence of $\mathrm{O}-\mathrm{H}$ groups are indicated by the $3433 \mathrm{~cm}^{-1}$ peak. This peak is believed to originate from the moisture or and alcohol or phenol group. The FTIR analysis of the composite clearly shows the presence of nettle fibres within the composite structure, whose presence results in various peaks depending on their chemical composition, while some small shifts were observed in some of PMMA's peaks, which could indicate a weak interaction between the two types of material.

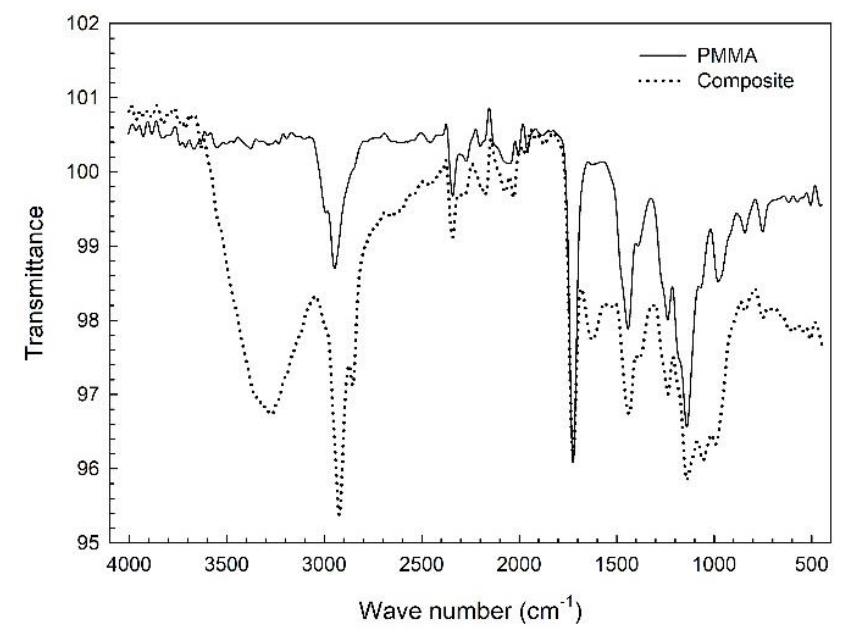

Fig. 3 FTIR spectra of PMMA and testing composite 


\subsection{X-Ray diffraction analysis of Nettle fibres}

The X-ray diffraction pattern of a typical crystal cage of cellulose within the nettle fibres is presented in Fig. 4. The theta $\theta$ values of the main patterns of cellulose fibres were observed at $16^{\circ}$ and $22.8^{\circ}$, corresponding to the (101) and (002) planes.

Peak (002) shows the largest crystal of cellulose. The crystallinity of the nettle fibres was found to be $71.6 \%$. In previous studies, the same method has been used to measure the crystallinity indices of various kinds of cellulose such as sisal, ketene, cannabis, and kenaf [30-31].

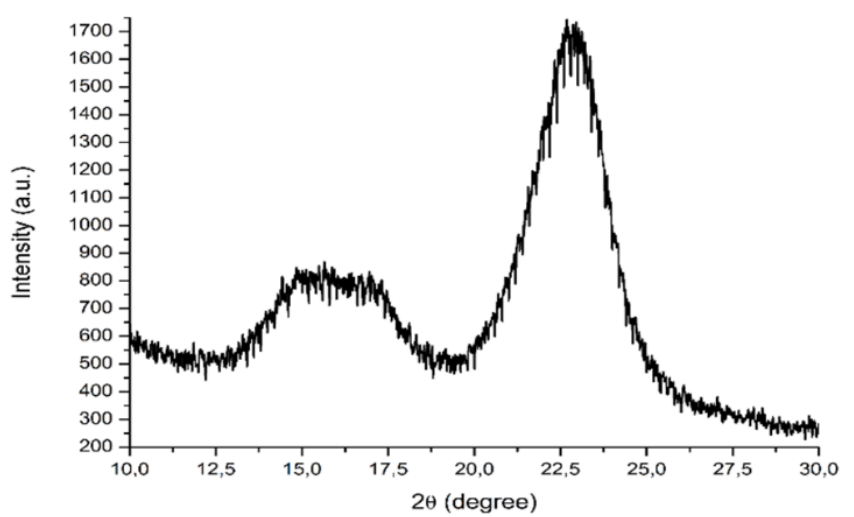

Fig. 4 XRD image of nettle fibres

\subsection{Bending strength and modules}

The load vs. displacement graphs obtained from the SEN-B Test are presented in Fig. 5. Depending on the amount of fibre added, the load values can increase and form a peak at composite samples containing a $10 \%$ volumetric fraction point.

The fibre volumetric fractions, bending modules and final stresses are presented in Fig. 6. Depending on the amount of fibre added, the bending strength values were found to be increase.

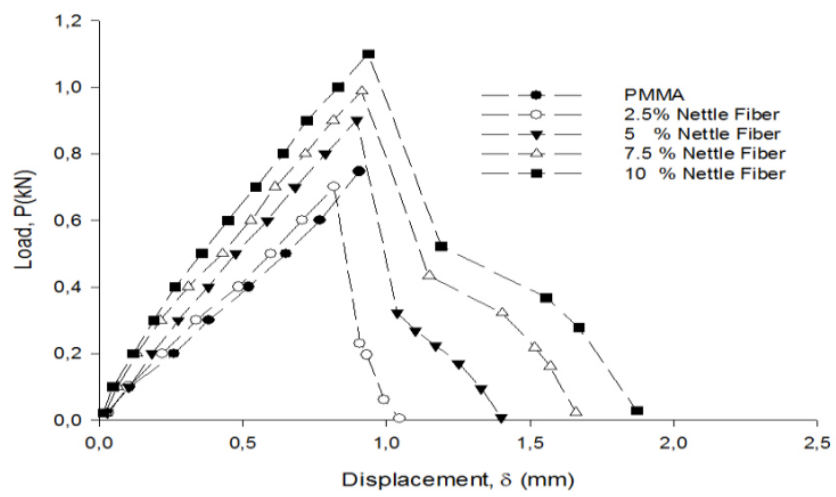

Fig. 5 Load-Displacement graph for testing composites

Adding 5\% fibre increased bending strength by $23 \%$ while modulus increased by $20 \%$. Respectively, adding $7.5 \%$ and $10 \%$ fibre increased bending strength $41 \%$ and $60 \%$ while modulus increased by $24 \%$ and $33 \%$.

In the analysis of $2.5 \%$ fibre added to the composite, the amount of fibre did not reach the critical value required to effect the bending strength while this amount of addition increased modulus only $2 \%$.

As can be seen in Fig. 5, the pure PMMA fractured in brittle manner. From Fig. 5, it can be seen that as the fibre volumetric fraction is increased $(<2.5 \%$ fibre ratio), the material becomes capable of bearing an increased load as well as exhibiting greater elongation without any damage. This result confirms that bending fracture increases energy consumption. Those results were found to be similar to those obtained in studies carried out on composite materials reinforced with various natural fibres (pineapple leaf fibre/sisal fibre, flax and cordenka) [29, 32-35].

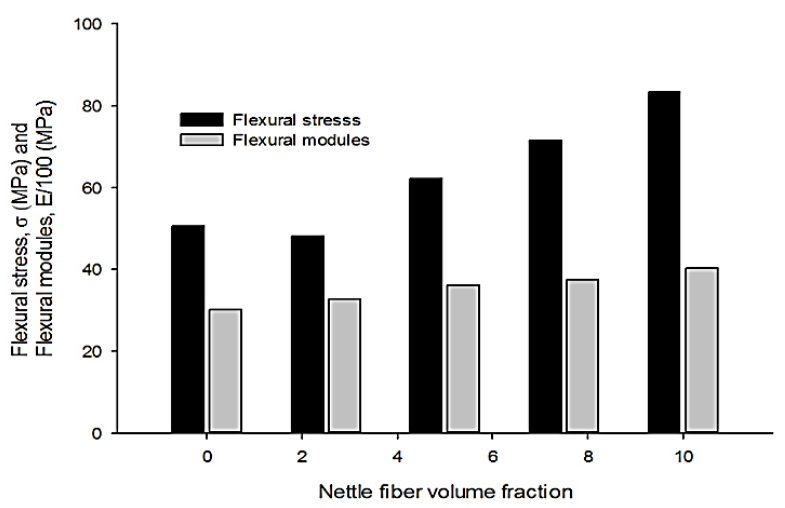

Fig. 6 Flexural stress and modules by percentage of nettle fibre composites

Its value is dependent on the geometrical dimensions of the material, the load types, and the location and direction of the crack. Fracture toughness is a characteristic of any material and defined by the critical stress intensity factor $K_{I C}$ under Mode I loading conditions.

$K$, identifies the level of "stress" on the tip of a crack while the fracture toughness is the highest level of stress intensity that a material can tolerate without cracking under certain conditions. When the stress intensity factor reaches $K_{I C}$, irregular cracking occurs. $K_{I C}$ values are used to determine the critical crack length when a certain level of stress is applied, or it may also be used to calculate the critical stress when there is a crack of known length in a part [36].

Various methods have been developed to determine the $K_{I C}$ In this study, the Standard and Compliance bending tests, and the $C_{T}$ method in tensile test were used to obtain $K_{I C}$, where a comparison of the results of these methods are presented in Fig. 11.

\subsubsection{Bending test}

\subsubsection{Initial notch depth method}

The initial notch depth method is a means of calculating the linear elastic fracture mechanics which can be used to obtain the stress intensity factor for a beam under TPB test conditions [37]. This method is based on calculating the critical stress intensity factor $K_{I C}$ using a single notch. The fracture values are calculated using the values obtained from samples with an $a / w$ ratio of 0.4 in the force crack mouth opening displacement graph, as shown in Fig. 7, which was obtained using Eq. (6) and Eq. (7) (ESM2). The fracture toughness of the standard samples was $2.5 \%, 5 \%, 7.5 \%$ and $10 \%$ reinforced were increased by $14 \%, 34 \%, 97 \%, 105 \%$ compared to the pure sample. These results are presented in Fig. 11 together with other results for the purposes of discussion. Similar results were in good agreement with the results of fractured toughness material studies reported for the TPB test [38]. 


\subsubsection{Compliance method}

Compliance $C$ is the ratio of $C_{M O D}$ over load and can be calculated via the compliance method, which is suitable for calculating the critical stress intensity factor of a brittle material [39].

In calculating $K_{I C}$, the data obtained from the compliance test in Fig. 7 and initial notch ratios, the data plotted in Fig. 8 were used. The derivative of gradient of the graph shown in Fig. 8 was used to calculate the fracture toughness values via Eq. (9). The fracture toughness values of materials according to the data obtained by the compliance method for $2.5 \%, 5 \%, 7.5 \%, 10 \%$ volume ratio composites were, respectively, $18 \%, 22 \%, 94 \%$, and $110 \%$.

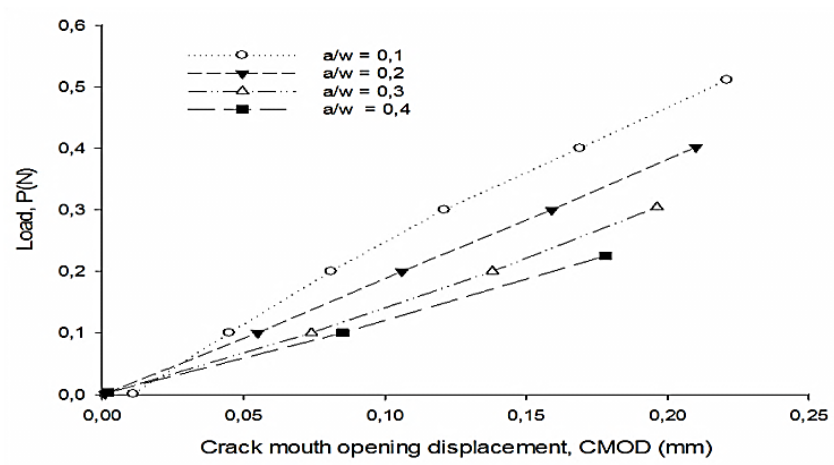

Fig. 7 Load vs. $C_{M O D}$ variations for $10 \%$ Nettle fibre-reinforced composites having various initial notch-todepth ratios (ESM 2)

Similar to this result, it was observed that $0.5 \mathrm{Wt} \%$ carbon nanotube added to an epoxy matrix increased the fracture toughness by $42 \%$ in the experiments performed using SENB samples [40].

$f=7,50 \times 10^{-3}-4,48 \times 10^{-4}(x)+1,03 \times 10^{-4}\left(x^{2}\right)-3,66 \times 10^{-6}\left(x^{3}\right)$

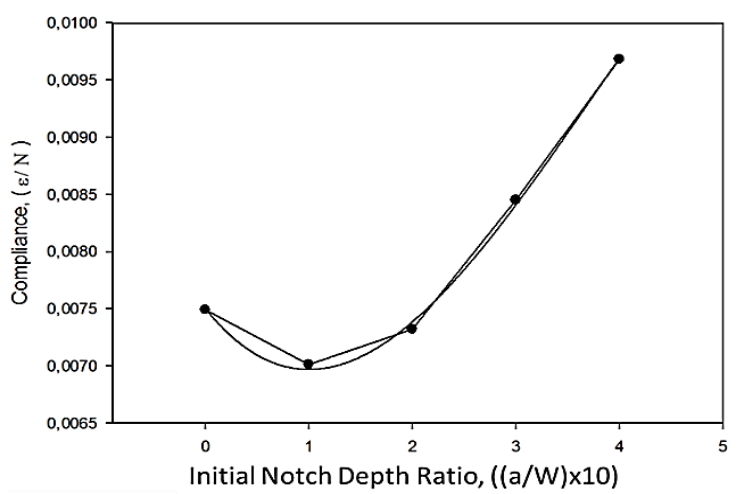

Fig. 8 Compliance vs. initial notch depth ratio of nettle fibre/PMMA composite (ESM3)

\subsubsection{Compact tension test}

This test is widely used for measuring the translaminar fracture toughness of composites [41]. The fracture toughness values of composites reinforced with nettle fibres were also determined by using the compact tension test. In Fig. 9, the crack images of the $10 \%$ reinforced composite and pure PMMA are shown.

It can be seen from Fig. 9 that there was ductile crack propagation in the reinforced composite, whereas the crack in PMMA was more brittle in nature. This mechanical behaviour originates from the greater fracture toughness of the composite which reinforced by the nettle fibres.

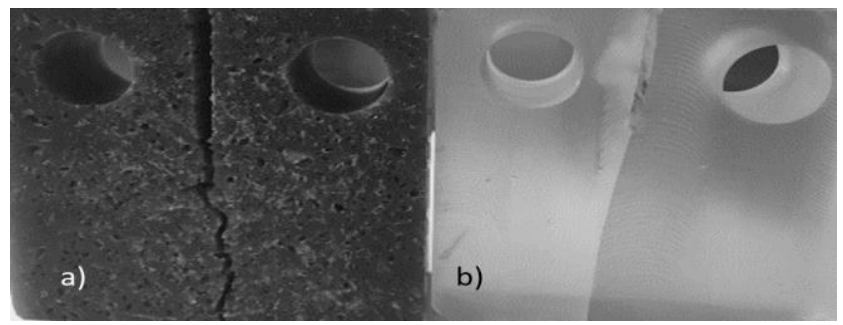

Fig. 9 Compact Tension Test Samples: a) $10 \%$ reinforced composite; b) pure PMMA

It can be seen from Fig.10 that the elongation of composites having $5 \%$ or more fibre content were increased, which is an indication of a more ductile composite. After $2 \mathrm{~mm}$ displacement, shear stresses became more effective, as indicated by the gradient of the graphs in Fig. 10 .

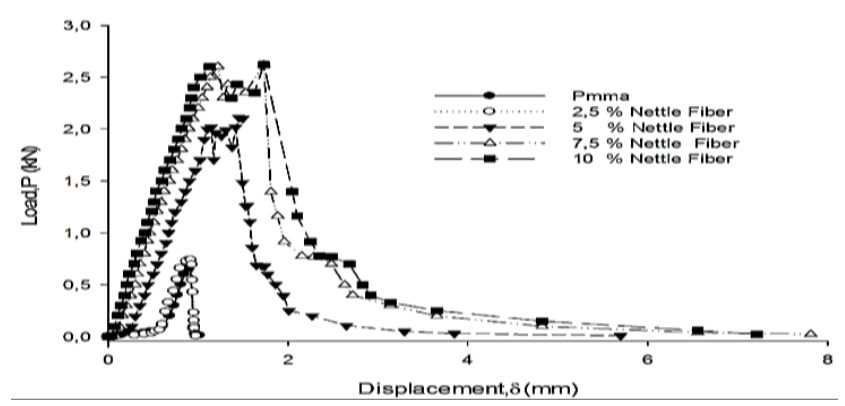

Fig. 10 Displacement change of PMMA-Nettle Fibre composites in $C_{T}$ specimens (ESM 4)

According to Figs. 9 and 10, the increase in fracture toughness obtained from composite samples in comparison to pure PMMA were increased by $12 \%, 27 \%, 87 \%$, and $81 \%$ using volumetric fractions of $2.5 \%, 5 \%, 7.5 \%$, and $10 \%$, respectively. These results were compatible to those reported in the literature [42].

$K_{I C}$ values calculated using the initial notch depth, compliance, and $C_{T}$ methods are presented in Fig. 11. As can be seen in this figure, depending on the amount of fibre added, the critical stress intensity factor increased by $105 \%$, $110 \%$, and $87 \%$ in comparison with the initial notch, Compliance, and $C_{T}$ methods, respectively $K_{I C}$ values for $10 \%$ volume fraction samples from the SENB and $C_{T}$ test results showed that the initial notch and Compliance values showed a reduced rate of increase, and $C_{T}$ values decreased. From this perspective, it can be said that the effect of porosity becomes evident when the volume fracture of the sample structure reaches $10 \%$.

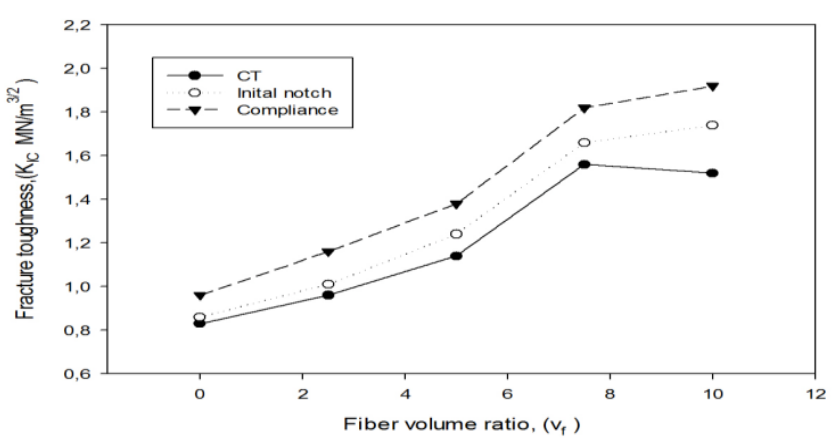

Fig. 11 Critical stress intensity factor versus nettle fibre reinforcement content using the, CT, initial notch and compliance methods 


\subsection{Morphology}

The SEM microphotograph of pure nettle and of fracture surfaces of nettle fibre/PMMA composites are presented in Fig. 12 [43]. Although the pure nettle fibre surface is almost smooth in appearance, the shape of the microfibrils, which is called the fibrillary orientation and is in $S$ form for nettle fibre, can be seen on the fibre itself (Fig. 12, a). Given the traces on the fracture surface of pure PMMA, it can be seen that there is very little plastic deformation and they fracture in a semi-brittle manner (Fig. 12, b). In Fig. 12, $\mathrm{c}$ and $\mathrm{d}$, the breaking photos for single nettle fibres within the composite can be seen. It is clear that the single fibre is damaged through delinking. Before the delinking, the nettle fibre deformed in plastic manner and thus absorbed a higher amount of energy.
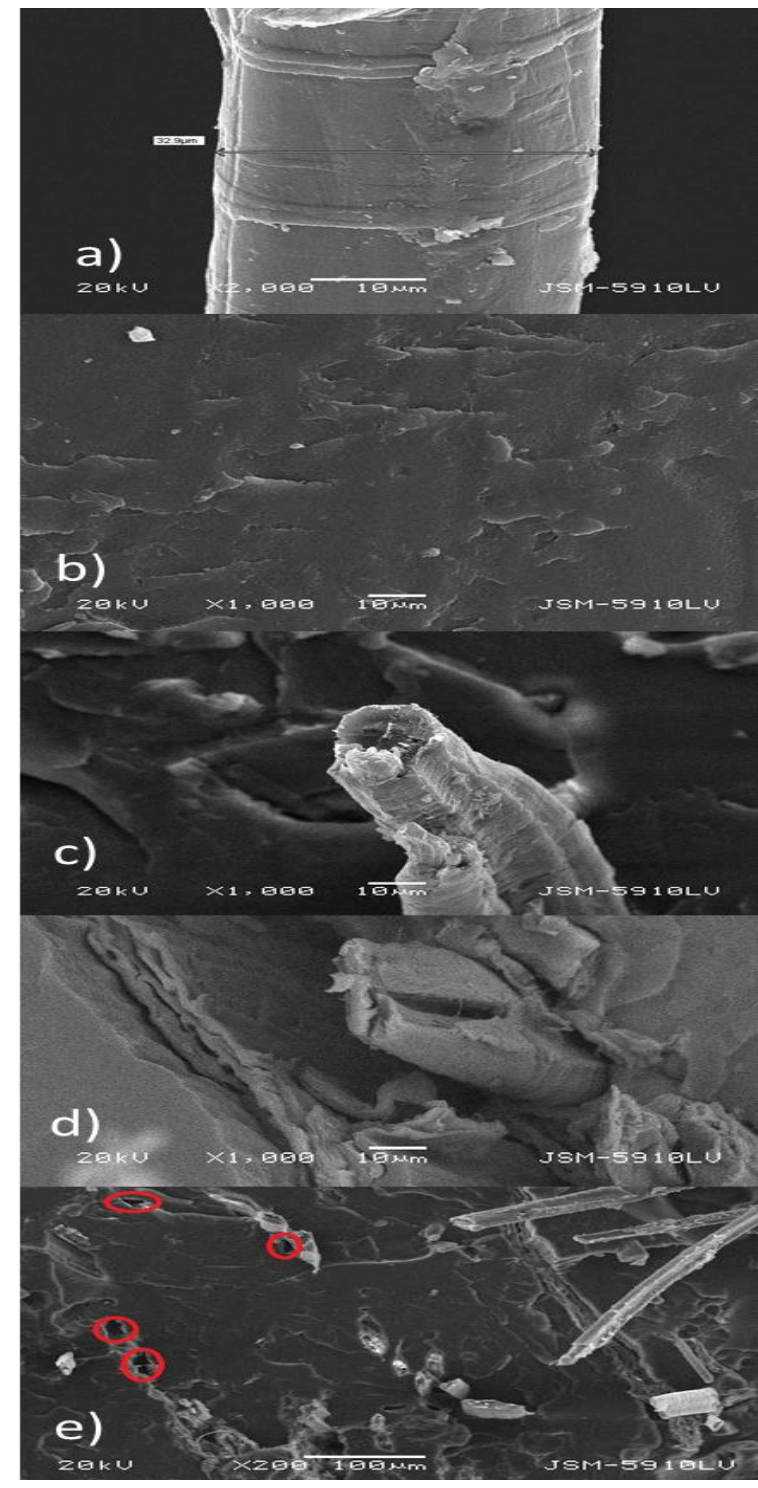

Fig. 12 SEM images of crack surfaces: a) single nettle fibre; b) surface of pure PMMA; c) damaged single fibre; d) post-test for single fibre; e) post-test for fracture surface

In Fig. 12, e, the image of the fracture surface of a composite with a $5 \%$ fibre volumetric fracture can be seen. From the visual investigation of the fracture surface, the effects of various fracture mechanisms can be observed. The presence of small holes in marked areas indicate the fibre pull-outs in those regions. In front of this region, it can be seen that the fibre fractures played a more effective role. All of these surface images reveal that the nettle fibre/PMMA composites absorbed the energy via various mechanisms during the breakage, and also reveals that their mechanical and fracture properties fracture were positively affected

\section{Conclusions}

This study revealed that it is possible to successfully develop a composite with improved mechanical and fracture properties by reinforcing, in our case, PMMA with nettle fibres. Compared to the pure PMMA matrix, the mechanical and fracture properties of nettle fibre/PMMA composites were significantly increased, where the fracture toughness value was increased two-fold.

Although CT values decreased at the maximum reinforcement rate, fracture values for composites tested with different fracture samples and methods showed a certain continuity. This result indicated that these methods can be used to determine the static fracture toughness of the composites so produced.

In this study, although the results of the tests using the standard calibration values (initial notch and compact test) were reduced, the values of the experimental calibration (compliance) were increased. These results revealed the importance of experimental calibration in order to obtain more sensitive values.

The positive damage tolerance of nettle fibre composites might be related to the complex energy loss processes occurring near the crack. Compared to the smooth fracture surfaces of PMMA, the unsmooth fracture surfaces were observed in composites because of pre-crack fissures propagating locally in different directions, as could be noted in Fig. 3. This formation results in a reduction of the sharpness of the crack tip and deviation of the crack. The significant increase in fracture toughness might be correlated with the concurrence and interaction of micro damage processes such as stable crack enlargement.

The physico-chemical interaction between the nettle fibres and matrix is thought to play an important role in determining the level of stress transfer at the fibre/matrix interface, and thus in the mechanical and fracture properties of the composite. In this study, modest mechanical results were achieved even when the extent of fibre reinforcement was relatively low; when compared to pure PMMA, this showed an increase of $103 \%$ in fracture toughness determined via the standard method, $105 \%$ in the Compliance, and $87 \%$ in the CT method.

The results obtained in this study suggest that natural fibres can easily be used as an alternative to fossil-fuelbased fibres. Due to environmental issues, naturel fibres are more effective and increased funding for studies into naturel fibre behaviours would be extremely beneficial.

\section{References}

1. Rwahwire, S.; Tomkova, B.; Periyasamy, AP.; Kale, BM. 2018. Green Composites for Automotive Applications, Chapter 3 - Green thermoset reinforced biocomposites Woodhead Publishing Series in Composites Science and Engineering, 61-80.

https://doi.org/10.1016/B978-0-08-102177-4.00003-3. 
2. Ashori, A. 2008. Wood-plastic composites as promising green-composites for automotiv eindustries, Bioresource T., 99:4661-7. https://doi.org/10.1016/j.biortech.2007.09.043.

3. Bhowmick, M.; Mukhopadhyay, SA.; Alagirusamy, A. 2012. Mechanical properties of natural fibre-reinforced composites, Textile Progress 44: 85. https://doi.org/10.1080/00405167.2012.676800.

4. Market Research Report, Natural Fiber Composites Market Analysis by Raw Material Segment Forecasts to 2024, Industry Report, 2024.

https://www.grandviewresearch.com/industry-analysis/natural-fiber-composites-market, 2016.

5. Luyt, A. S.; Malunka, M. E.; 2005, Composites of lowdensity polyethylene and short sisal fibres: the effect of wax addition and peroxide treatment on thermal properties, Thermochim Acta 426(1-2): 101-7. https://doi.org/10.1016/j.tca.2004.07.010.

6. Gassan, J.; Bledzki, A. K. 1997.The influence of fibersurface treatment on the mechanical properties of jutepolypropylene composites. Composites Part A: Applied Science and Manufacturing 28(12):1001-1.

7. Bledzki, A. K.; Mamun, A. A.; Volk, J. 2010. Physical, chemical and surface properties of wheat husk, rye husk and soft wood and their polypropylene composites. Composites Part A: Applied Science and Manufac, 41(4): 480-4.

https://doi.org/10.1016/j.compositesa.2009.12.004.

8. Mohd Nor, M. J.; Abdullah, S.; Jamaluddin, N.; Ismail, R.; Mohamed, S. H.; Arifin, A. 2007. Study on the dynamic characteristic of coconut fiber reinforced composites, Regional Conference on Engineering Mathematics, Mechanics, Manufac. \& Architecture (EM*ARC), Putrajaya, Malaysia.

9. Keck, S.; Fulland, M. 2016. Effect of fibre volume fraction and fibre direction on crack paths in flax fibre-reinforced composites, Eng. Fracture Mech. 167 201-9. https://doi.org/10.1016/j.engfracmech.2016.03.037.

10. Vipulanandan, C.; Dharmarajan, N.; 1989. Fracture properties of particle filled polymer composites. Journal of composite materials 23(8):846-8.

11. Araki, W.; Nemoto, K.; Adachi, T.; Yamaji. A. 2005.Fracture toughness for mixed mode I/II of epoxy resin 53(3): 869-5. https://doi.org/10.1016/j.actamat.2004.10.035.

12. Pini, T.; Briatico-Vangosa, F.; Frassine, R.; Marta Rink, M. 2017. Fracture toughness of acrylic resins: viscoelastic effects and deformation mechanisms, Polymer engineering and science 58: 369-6. https://doi.org/10.1002/pen.24583.

13. Marcovich, N. E.; Aranguren, M. I.; Reboredo, M. M. 2001. Modified wood flour as thermoset fillers Part I. Effect of the chemical modification and percentage of filler on the mechanical properties, Polymer 42(2): 815 8. PII: S0032-3861(00)00286-X.

14. Yesgat, A.; Kitey, L. 2016. Effect of filler geometry on fracture mechanisms in glass particle filled epoxy composites, Engineering Fracture Mechanics 160: 22-41.

15. Gentile, D. 2018. Experimental characterization of interlaminar fracture toughness of composite laminates assembled with three different carbon fiber lamina 43 : 155-0.

https://doi.org/10.3221/1gf-es1s.43.12.
16. Yusuo, W.; Xiaozhi, H. 2017. Determination of tensile strength and fracture toughness of granite using notched three-point-bend samples, Rock Mech. Rock Eng. 50: $17-8$. https://doi.org/10.1007/s00603-016-1098-6.

17. Ortega, A.; Maimí, P.; González, E. V.; Ripoll, L. I. 2014. Compact tension specimen for orthotropic materials Composites Part A: Applied Sci. and Man. 63: 85-3. https://doi.org/10.1016/j.compositesa.2014.04.012.

18. Mollenhauer, D.; Ward, L.; Iarve, E.; Putthanarat, S.; Hoos, K.; Hallett, S.; Li, X. 2012. Simulation of discrete damage in composite Overheight Compact Tension specimens, Composites Part A: Applied Science and Manufacturing 43(10): 1667-9.

https://doi.org/10.1016/j.compositesa.2011.10.020.

19. Baley, C.; Lamy, B. 2000. Mechanical properties of the flax fibers used as composite reinforcement materials. RCMA (Revue des Composites et des Matériaux Avancés) 10(1): 7-24.

20. Huang, G. 2005. Nettle (Urtica cannabina L) fibre, properties and spinning practice, Journal of the Textile Institute 96(1): 11-1. https://doi.org/10.1533/joti.2004.0023.

21. Barlow, C. Y.; Neal, D. 2011. Fibre from stinging nettles, Cambridge University, Department of Engineering, United Kingdom, https://www.srcf. ucam.org/awtbi/documents/Fibrefromstingingnettles.pdf.

22. Bodros, E.; Baley, C. 2008. Study of the tensile properties of stinging netle fibres (Urtica dioica), Material Letters 62: 2143-5. https://doi.org/10.1016/j.matlet.2007.11.034.

23. Zhang, X.; Sun, Z.; Hu, X. 2014. Low temperature fracture toughness of PMMA and crack-tip conditions under flat-tipped cylindrical indenter, Polymer Testing $38 ; 57-3$.

https://doi.org/10.doi.org/10.1016/j.polymertesting.201 4.06.009.

24. Marshall, G. P.; Coutts, L. H.; Williams, J. G. 1974. Temperature effects in the fracture of PMMA, Journal of Materials Science 9(9):1409-9.

25. Roe, P. J.; Ansell, M. P. 1985. Jute-reinforced polyester composites, Journal of Materials Sci. 20(11):4015-20.

26. Ennis, C. P.; Kaiser, R. I. 2010. Mechanistical studies on the electron-induced degradation of polymethylmethacrylate and Kapton, Physical Chemistry Chemical Physics 12(45):14902-15. https://doi.org/10.1039/C0CP01130D.

27. Joonobi, M.; Harun, J.; Tahir, P. M.; Zaini, L. H.; SaifulAzry, S.; Makinejad, M. D. 2010. Characteristic of nanofibers extracted from kenaf core, BioResources 5(4): 2556-66.

28. Roncero, M. B.; Torres, A. L.; Colom, J. F.; Vidal, T. 2005. The effect of xylanase on lignocellulosic components during the bleaching of wood pulps, Bioresource Tech. 96(1): 21. https://doi.org/10.1016/j.biortech.2004.03.003.

29. Atkins, A. G.; Mai, Y. W. 1985. Elastic and Plastic Fracture: Metals, Polymers, Ceramics, Composites, Biological Materials. Ellis Horwood, (New York: Halsted Press).

30. Rong, M. Z.; Zhang, M. Q.; Liu, Y.; Yang, G. C.; Zeng, H. M. 2001. The effect of fiber treatment on the mechanical properties of unidirectional sisal-reinforced 
epoxy composites, Composites Science and technology 61(10):1437-7.

https://doi.org/10.1016/S0266-3538(01)00046-X.

31. Tserki, V.; Zafeiropoulos, N. E.; Simon, F.; Panayiotou, C. 2005. A study of the effect of acetylation and propionylation surface treatments on natural fibres. Composites Part A: applied science and manufacturing 36(8):1110-18.

https://doi.org/10.1016/j.compositesa.2005.01.004.

32. El-Sakhawy, M.; Hassan, M. L. 2007. Physical and mechanical properties of microcrystalline cellulose prepared from agricultural residues, Carbohydrate Polymers 67(1):1-10. https://doi.org/10.1016/j.carbpol.2006.04.009.

33. Mwaikambo, L. Y.; Ansell, M. P. 2002. Chemical modification of hemp, sisal, jute, and kapok fibers by alkalization, Journal of Applied Polymer Science 84(12):2222-34. https://doi.org/10.1002/app.10460.

34. Meredith, J.; Coles, S. R.; Powe, R.; Collings, E.; Cozien-Cazuc, S.; Weager, B.; Müssig, J.; Kirwan, K. 2013. On the static and dynamic properties of flax and Cordenka epoxy composites. Composites Science and Technology 2013; 80: 31-8. https://doi.org/10.1016/j.compscitech.03.003.

35. Mishra, S.; Mohanty, A. K.; Drzal, L. T.; Misra, M.; Parija, S.; Nayak, S. K.; Tripathy, S. S. 2003. Studies on mechanical performance of biofibre/glass reinforced polyester hybrid composites, Composites Science and Technology 63(10):1377-5. https://doi.org/10.1016/S0266-3538(03)00084-8.

36. Samanci, A. 2012. Fracture behavior of woven steel fiber reinforced and sand particle filled polymer composites, Construction and Building Materials 26(1):167-1. https://doi.org/10.1016/j.conbuildmat.2011.06.006.

37. Tada, H.; Paris, P. C.; Irwin, G. R. 2000. The Stress Analysis of Crack Handbook, American Society of Mechanical Engineers. ISBN-13:978-0791801536.

38. Paradkar, A. G.; Ravali, N. S.; Prasad, N. E. 2017. Mechanical behavior of 2D and 3D weaved SiC-matrix, carbon-continuous-fibre-reinforced composites: Part 2. Fracture toughness under static loading conditions, Engineering Fracture Mechanics, 182:52-1. https://doi.org/10.1016/j.engfracmech.2017.07.003.

39. Underwood, J. H.; Chait, R.; Smith, C. W.; Wilhem, D. P.; Andrews, W. R.; Newman, J. C. 1986. Fracture Mechanics: Seventeenth Volume, ASTM International.

40. Hsieh, T. H.; Kinloch, A. J.; Taylor, A. C.; Kinloch I. A. The effect of carbon nanotubes on the fracture toughness and fatigue performance of a thermosetting epoxy polymer, J. Mater. Sci. 46:7525-7535. https://doi.org/10.1007/s10853-011-5724-0.

41. Laffan, M. J.; Pinho, S. T.; Robinson, P.; McMillan, A. J. 2012. Translaminar fracture toughness testing of composites: a review, Polymer testing 31(3): 481-9. https://doi.org/10.1016/j.polymertesting.2012.01.002.

42. Low, I. M.; McGrath, M.; Lawrence, D.; Schmidt, P.; Lane, J.; Latella, B. A.; Sim, K. S. 2007. Mechanical and fracture properties of cellulose-fibre-reinforced epoxy laminates, Composites Part A: Applied Science and Manufacturing 38(3): 963-4.

https://doi.org/10.1016/j.compositesa.2006.06.019.

43. Büyükkaya, K. 2017. Investigation of Mechanical Behavior of Hybrid Composites Nettle Fiber-Hazelnut Shell. Gazi Üniversitesi Fen Bilimleri Dergisi Part C: Tasarım ve Teknoloji 5 (4): 133-144. https://doi.org/10.29109/http-gujsc-gazi-edutr.337247Standard Test Method for Determining $J-R$ Curves. ASTM E1152-87. 11p.

\section{K. Büyükkaya, F. Güner}

\section{DETERMINATION OF STATIC FRACTURE TOUGHNESS OF NETTLE FIBRE (URTICA DIOICA) / POLYMETHYLMETHACRYLATE COMPOSITES USING DIFFERENT FRACTURE METHODS}

S u m m a r y

In this study, the breaking behaviour of polymethylmethacrylate reinforced with nettle fibre was investigated experimentally. Single edge notched bending (SENB) and compact test(CT) specimens were produced to include notches in various ratios. The Mode I fracture behaviour of samples were determined utilizing static fracture toughness experiments such as the Three Point Bending (TPB) and Compact Tensile tests. The fracture toughness (KIC) was investigated using the TPB Test (Compliance and Initial notch method), and Compact Tension test. The bending module and bending stresses were also determined. It was found that nettle-fibre reinforcement improves the bending strength of the composite by $60 \%$ and improves the fracture toughness more than two-fold.

Keywords: composite, fracture toughness, mechanical properties, nettle fibre, PMMA.

Received May 02, 2019

Accepted April 15, 2020 